Artigo recebido em

29/03/2015

Aprovado em

17/04/2015

Maíra Sousa

Universidade Federal do Rio Grande do Sul (UFRGS) jornalista.maira@gmail.com

Doutoranda em

Comunicação e Informação na Universidade Federal do Rio Grande do Sul (PPGCOM|UFRGS).

Mestre em Jornalismo pela Universidade

Federal de Santa Catarina (POSJOR|UFSC)

1 Uma versão preliminar deste artigo foi apresentada no $12^{\circ}$ Encontro Nacional de Pesquisadores em Jornalismo - SBPJor, em Santa Cruz do Sul (RS), novembro de 2014. Esta versão possui algumas alterações.

\title{
Reconfigurações do jornalismo: das páginas impressas para as telas de smartphones e tablets ${ }^{1}$
}

\author{
Maíra Sousa
}

\begin{abstract}
Resumo
Assim como a sociedade, o jornalismo também passa por reconfigurações. Com a emergência das tecnologias digitais no século XX, empresas jornalísticas precisaram se adaptar e investir em novos produtos, a fim de conquistar novos públicos e manter o antigo, concomitantemente. De cunho teórico, este artigo busca discutir as reconfigurações pelas quais o jornalismo tem passado desde a emergência das tecnologias digitais, com ênfase nos dispositivos móveis, considerando o atual processo de convergência, e, consequentemente, a distribuição de conteúdo em multiplataformas. A metodologia utilizada foi a pesquisa bibliográfica.
\end{abstract}

\section{Palavras-chave}

Paradigmas Jornalísticos, Convergência Jornalística, Dispositivos Móveis.

\begin{abstract}
Just as society, the journalism also undergoes reconfigurations. With the emergence of digital technologies in the XX century, news organizations have adapted and invest in new products, in order to gain new audiences and keep the old concomitantly. The theoretical article aims to discuss the reconfiguration why journalism has passed since the emergence of digital technologies, with emphasis on mobile devices, considering the current convergence process, and consequently, the distribution of multi-platform content. The methodology used was the bibliographic research.
\end{abstract}

\section{Keywords}

Paradigms Journalistic, Journalistic Convergence, Mobile Devices. 
${ }^{2}$ A pesquisa Reuters Institute Digital News Report 2014 foi realizada pelo Reuters Institute for the Study of Journalism entre janeiro $e$ fevereiro de 2014 em dez países (incluindo o Brasil). Disponível em https://reutersinstitute.politics.ox.ac. $u k /$ sites/default/files/ Reuters\%20Institute $\% 20$ Digital\%20 News\%20Report\%20 2014.pdf. Acesso em: 23 jun 2014.

${ }^{3}$ Neste artigo usamos a tradução da edição brasileira que está em revisão para publicação.

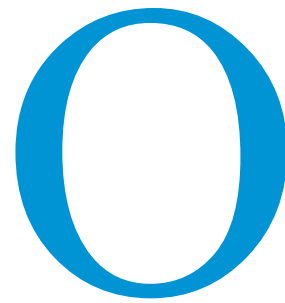

uso de smartphones e tablets aumentou significativamente nos últimos anos.

Com isso, as pessoas estão consumindo notícias por meio de uma maior quantidade de dispositivos. Contudo, o computador ainda é o mais usado, dentre os artefatos digitais, para consumo de informações jornalísticas na internet. Segundo os dados do Reuters Institute Digital News Report 2014², mais de um terço dos usuários entrevistados (39\%) consomem notícias em dois ou mais dispositivos. Quando o assunto é cobrança pelo conteúdo, o número de pessoas que pagam por notícias digitais manteve-se estável ao longo do último ano (43\% obtêm algum tipo de assinatura). No entanto, dentre aqueles que não pagam, $15 \%$ se dizem propensos a pagar futuramente.

Diante desse contexto, com o objetivo de conquistar novos públicos e manter o antigo, concomitantemente, as tradicionais organizações jornalísticas têm investido na distribuição de conteúdo em multiplataformas, uma das estratégias do processo que vem sendo definido como convergência jornalística (BARBOSA， 2009; SALAVERRÍA, 2010; SALAVERRÍA, GARCIAAVILÉS, MASIP, 2010) ou jornalismo convergente (KOLODZY, 2006).

De caráter teórico, este artigo tem objetivo de discutir as reconfigurações pelas quais o jornalismo tem passado desde a emergência das tecnologias digitais, dando ênfase aos dispositivos móveis, considerando o atual processo de convergência, e, consequentemente, a distribuição de conteúdo em multiplataformas.
A metodologia utilizada foi a pesquisa bibliográfica.

Optamos por usar a palavra reconfiguração por conta da terceira lei da cibercultura proposta por Lemos (2005): "a lei da reconfiguração". Segundo o autor, com a emergência das tecnologias informacionais, a sociedade tem passado por uma reconfiguração geral. Nesse sentido, ele afirma que "tudo muda, mas nem tanto" (LEMOS, 2005, p. 3), não existindo uma substituição ou aniquilamento de meios, mas sim uma reconfiguração de "práticas, modalidades midiáticas, espaços, sem a substituição de seus respectivos antecedentes". Assim, a ideia de reconfiguração pode ser entendida a partir da "modificação das estruturas sociais, das instituições e das práticas comunicacionais" (LEMOS, 2005, p. 3). Utilizamos o termo neste sentido porque entendemos que o jornalismo é uma prática social e, sendo assim, também passa por reconfigurações.

O texto está dividido da seguinte forma: no primeiro tópico, "Paradigmas Jornalísticos", apresentamos a tipologia proposta pelos canadenses Brin, Charron e Bonville $(2004)^{3}$ para caracterizar as formas específicas de jornalismo de cada época. Considerando que vivemos em um novo paradigma, definido como Jornalismo de Comunicação, o segundo tópico, "Convergência Jornalística", discorre sobre este processo que tem como resultado a distribuição de conteúdo em multiplataformas. Por último, no terceiro tópico, "Reconfigurações do Jornalismo", discutimos as principais transformações sofridas desde a emergência das tecnologias digitais e a informatização das organizações noticiosas ainda na década de 1960. Como o foco deste artigo está nas 
tecnologias digitais móveis, no subtópico "Transformações e desafios frente aos dispositivos móveis: smartphones e tablets" apresentamos algumas inovações sofridas pelo jornalismo atualmente (especialmente no que diz respeito aos seus produtos, modelo de negócios e ao papel do jornalista).

\section{Paradigmas jornalísticos}

O jornalismo é uma prática social, e, assim como a sociedade, também passa por transformações e reconfigurações. As inovações tecnológicas sempre marcaram a história do jornalismo. A imprensa de tipos móveis, o telégrafo, o telefone, os computadores e as mídias móveis são exemplos de tecnologias que modificaram as rotinas de produção noticiosa em diferentes épocas.

No livro Nature et transformation $\mathrm{du}$ journalisme - théorie et recherches empiriques (2004), os canadenses Brin, Charron e Bonville buscam trazer debates teóricos e metodológicos sobre o jornalismo, considerando o seu atual estado e as suas modificações espaçotemporais. Para os autores, “o jornalismo real é um objeto infinitamente complexo e não está conformado, jamais, na sua história, nem a um nem a outro dos modelos teóricos puros" (BRIN, CHARRON, BONVILLE, 2004, p. 14-15). Então, a partir do método dos tipos ideais de Max Weber, da definição de paradigma de Thomas Kunh e considerando a história da imprensa na América do Norte, os autores propõem quatro paradigmas jornalísticos, os quais foram caracterizados por formas específicas e singulares de praticar o jornalismo (BRIN, CHARRON,
BONVILLE, 2004, p. 2-4):

- Jornalismo de transmissão (século XVII): as chamadas gazetas eram feitas por impressores, que tinham como objetivo difundir correspondências, anúncios e informações em geral. Não existia uma identidade de gazeteiro ou de jornalista.

- Jornalismo de opinião (século XIX): surge em um contexto de transformações das intituições políticas. $\mathrm{O}$ gazeteiro passa a ter uma identidade e coloca o jornal a serviço das lutas políticas. O chamado jornal de opinião passa a ser financiado por leitores, políticos, mas também pela publicidade.

- Jornalismo de informação (século XIX): em um contexto de mudanças comerciais e sociais, que favoreceram a melhoria das condições dos bens de consumo, o jornal passa a ser um negócio lucrativo. Assim, assuntos relacionados à política são relativamente abandonados e os jornais passam a publicar temas que possam interessar a um maior número de leitores. A ampliação da produção e distribuição desse produto foi possível graças às condições técnicas e econômicas existentes na época: telégrafo, ferrovia, telefone, rotativa.

- Jornalismo de comunicação (final do século XX): surge em um momento de multiplicação dos suportes midiáticos e dos serviços de informação, que foram impulsionados pela busca por novos públicos e pelas inovações técnicas, movimentos de desregulamentação e de liberalização dos mercados. A principal característica desta fase é diversificação e superabundância de oferta:

A imprensa escrita cotidiana e as 
grandes redes de televisão, que dominam a indústria dos mídias, veem suas parcelas e mercado esfacelar-se a favor de novas mídias, mais especializadas, mais inovadoras, menos respeitadoras das normas estabelecidas. A multiplicação e a miniaturização dos equipamentos, desenvolvimento telecomunicações e, mais recentemente, a implantação da internet rápida, eis aí o tanto de técnicas onde o uso tende a colocar em questão as normas $\mathrm{e}$ as práticas usuais de produção, de difusão e de consumo da informação e que colocam produtores e consumidores de informação em um ambiente midiático em plena mutação (BRIN, CHARRON, BONVILLE, 2004, p. 4).

Os autores canadenses veem as transformações dos paradigmas como mudanças nas estruturas sociais nas quais a imprensa está imersa. Portanto, num momento em que a sociedade passa por grandes transformações devido às tecnologias digitais que, dentre outras coisas, modificam a relação de tempo e de espaço estabelecida anteriormente, o jornalismo também é reconfigurado.

Para uma melhor compreensão desses processos pelos quais as organizações jornalísticas têm passado e das características do atual paradigma do jornalismo de comunicação caracterizado principalmente pela diversificação e pela superabundância da oferta - é necessário discorrermos sobre o que vem sendo definido como convergência jornalística ou jornalismo convergente.

\section{Convergência jornalística}

No contexto da comunicação a palavra convergência não é nova, contudo vem adquirindo outros usos. Se na década de 1970 era utilizada para se referir à relação entre os computadores e as s telecomunicações, a partir de 1990 passou a ser associada ao desenvolvimento tecnológico digital, à integração de texto, imagem, som e aos diversos elementos da mídia. Entretanto, foi no final dos anos 1990 que o termo ganhou certo protagonismo, resultado das alterações ocorridas nos veículos de comunicação que precisaram se adaptar às tecnologias digitais para manter sua sobrevivência e lucratividade.

A convergência envolve as antigas e as novas mídias, assim como os produtores e os consumidores, que agora também produzem informações. Jenkins (2009) aborda a convergência a partir de transformações técnicas, mercadológicas, culturais e sociais. Segundo o autor, "a convergência envolve uma transformação tanto na forma de produzir quanto na forma de consumir os meios de comunicação" (JENKINS, 2009, p. 44). Para ele, esse é um processo contínuo que compreende:

O fluxo de conteúdos através de múltiplas plataformas da mídia, a cooperação entre múltiplos mercados midiáticos e o comportamento migratório dos públicos dos meios de comunicação, que vão a quase qualquer parte em busca das experiências de 
entretenimento que desejam (JENKINS, 2009, p. 29).

É um processo que "altera as relações entre tecnologias existentes, indústrias, mercados, gêneros e públicos. [...] altera a lógica pela qual a indústria midiática opera e pela qual os consumidores processam a notícia e o entretenimento" (JENKINS, 2009, p. 43).

$\mathrm{Na}$ tentativa de sistematizar a evolução do termo, os autores espanhóis Salaverría, Garcia Avilés e Masip o classificam a partir de três fases cronológicas (2010, p. 44-47):

$1^{\text {a }) ~ C o n v e r g e ̂ n c i a ~ c o m o ~ p r o d u t o: ~ s u a ~}$ definição estava relacionada ao processo de união das tecnologias a partir da combinação de códigos linguísticos diferentes propiciados pela digitalização. Nessa fase, o conceito ainda era confundido com o de multimídia;

$\left.2^{\mathrm{a}}\right)$ Convergência como sistema: eram considerados aspectos não apenas instrumentais, mas também outros âmbitos de produção e de consumo. Era apresentada como o resultado de diversas esferas que se interconectam e se influenciam;

$3^{a}$ ) Convergência como processo: esse estágio não exclui o caráter sistêmico da convergência, no entanto, a considera também como um processo. Assim, ela é interpretada como um processo longitudinal, constituído por diversas etapas que têm como meta a integração. Essa fase tem uma estreita relação com o jornalismo, sendo considerada uma subvariante que ganhou muitos adeptos nos últimos anos.

A convergência pode ser considerada, segundo Kolodzy (2006), uma saída às mudanças tecnológicas, sociais e econômicas que afetaram tanto o público consumidor como a indústria noticiosa: "É uma resposta a duas tendências aparentemente dicotômicas - a fragmentação da audiência de notícias e a consolidação da propriedade dos grandes grupos de mídia" (KOLODZY, 2006, p. 11, tradução nossa). O jornalismo convergente, termo usado pela autora, seria uma maneira de pensar os processos de produção e distribuição da informação, usando todas as mídias para atrair novos consumidores e segurar os atuais:

Tem como objetivo abordar a crescente fragmentação da audiência, ao trabalhar com o avanço da consolidação da propriedade dos grandes grupos de mídia. [...] A convergência redireciona o jornalismo à sua missão principal - informar o público sobre seu mundo, da melhor forma possível (KOLODZY, 2006, p. 24, tradução nossa).

Assim, o jornalismo convergente busca reconhecer as propriedades de cada meio, para usá-las com o intuito de atrair a atenção do público cada vez mais fragmentado e disperso, e que nem sempre busca as notícias pelos veículos tidos como tradicionais. Ainda de acordo com a autora, "o jornalismo convergente fornece notícias e informações em mais de um formato, usando os pontos fortes de cada um para melhor servir o público de notícias" (KOLODZY, 2006, p. 21, tradução nossa).

Nesse ambiente, a comunicação é caracterizada pelo imediatismo, pela multimidialidade, pela interatividade, 
participação, pelo aprofundamento, estrutura não linear e personalização (SALAVERRÍA, GARCIA AVILÉS, MASIP, 2010). A partir desse cenário, os autores definem convergência jornalística como:

Um processo multidimensional que, facilitado pela implantação generalizada das tecnologias digitais da telecomunicação, afeta o âmbito tecnológico, empresarial, profissional e editorial dos meios de comunicação, propiciando uma integração de ferramentas, espaços, métodos de trabalho e linguagens anteriormente desagregadas, de forma que os jornalistas elaboram conteúdos que são distribuídos através de múltiplas plataformas, mediante as linguagens próprias de cada uma (SALAVERRÍA, GARCIA AVILÉS, MASIP, 2010, p. 59, tradução nossa).

Para Barbosa (2009), a convergência jornalística é uma subconvergência que está em curso, em um panorama mais abrangente, caracterizada pela:

Integração entre meios distintos; a produção de conteúdos dentro do ciclo contínuo 24/7; reorganização das redações; jornalistas que são platformagnostic, isto é, capazes de tratar a informação - a notícia - de maneira correta seja para distribuir no impresso, na web, nas plataformas móveis, etc; a introdução de novas funções além de habilidades multitarefas para os jornalistas; comunidade/ audiência ativa atuando segundo o modelo Pro-Am (profissionais em parceria com amadores); emprego efetivo da interatividade, do hipertexto e da hipermídia para a criação de narrativas jornalísticas originais. (BARBOSA, 2009, p. 3-4)

No jornalismo, esse processo aponta para aspectos relacionados às tecnologias, aos veículos noticiosos, à organização das redações, aos profissionais, às audiências e aos conteúdos (em todas as fases de produção, circulação e consumo). Assim, Salaverría (2010, p. 32-39) indica quatro áreas fundamentais da estrutura da convergência: 1) a tecnológica, onde um mesmo conteúdo informativo pode ser consumido instantaneamente a partir de múltiplos suportes e canais; 2) a empresarial, com novas formas de organização logística, a fim de melhorar a produtividade; 3) a profissional, uma vez que o perfil do jornalista passa a ser polivalente. Assim, ele precisa produzir todo o conteúdo (texto, foto, vídeo) para várias mídias de um mesmo jornal; 4) todas essas modalidades resultam na convergência de conteúdo, pois favorecem a "crescente hibridação de conteúdos e formatos oferecidos ao público através de diversas plataformas" (SALAVERRÍA, 2010, p. 39, tradução nossa).

\section{Reconfigurações do jornalismo}

Os jornais impressos têm enfrentado diferentes tipos de crise desde a década de 1960, quando ocorreu a informatização das empresas jornalísticas (ADGHIRNI, 
2012; MULLER, 2012). O processo começou bem antes da chegada da internet comercial, pelos setores administrativos e comerciais, e só chegou às redações nas duas décadas seguintes. Economicamente, significou aumento de produtividade e diminuição de custos (MULLER, 2012). Contudo, no que diz respeito ao processo de trabalho, a informatização pode ser comparada à mecanização da imprensa no século XIX, quando ocorreu a extinção de funções. Dessa forma, além do desaparecimento de funções, "estabeleceu-se uma tendência de que um mesmo profissional assumisse a responsabilidade por várias mídias, fenômeno que se acentuou durante a década de 1990 na medida em que se acentuou o que se convencionou chamar convergência das mídias" (MULLER, 2012, p. 154).

Além dos rearranjos entre setores e funções, dentre as principais mudanças ocorridas nas empresas jornalísticas no final do século XX podemos citar a alteração da estrutura financeira com a abertura de capital de muitas empresas que tradicionalmente eram familiares (MULLER, 2012). Ainda segundo Muller (2012, p. 150), “o advento da era digital colocou em xeque todo o modelo de negócio dessas empresas, impondolhes o desafio de se reinventarem ou sucumbirem".

O desenvolvimento de redes de informação e de comunicação fez com que empresas que eram tradicionalmente do ramo de telecomunicações e informática passassem a atuar na produção de conteúdo na década de 1990. A partir de 1995, com a chegada da internet comercial no Brasil, as organizações jornalísticas passaram a ter websites.

A rapidez sempre foi uma das marcas da produção jornalística, mas as tecnologias digitais aceleraram esse processo ainda mais nos últimos 20 anos, podendo ser considerada uma das principais mudanças estruturais do jornalismo (ADGHIRNI, 2012). Nesse sentido, Adghirni (2012, p. 65) afirma que a internet provocou um dos aspectos mais graves da crise dos jornais impressos: o envelhecimento precoce do produto notícia.

O modo de fazer jornalístico passou por transformações profundas. Uma das principais mudanças apontadas pela autora é o fato de os jornalistas conhecerem, em tempo real, a reação do público e a forma como as empresas concorrentes estão cobrindo o mesmo fato, podendo modificar rapidamente o conteúdo produzido, o que a autora chama de interatividade e reflexividade inédita (ADGHIRNI, 2012).

Nesse sentido, ao falar do paradigma jornalístico de comunicação, os autores canadenses propõem a noção de "hiperconcorrência" para tratar das estratégias que objetivam chamar a atenção do público:

Os jornalistas devem compor com uma situação na qual o público, constantemente solicitado por uma oferta de informação superabundante tende a elevar seu limiar de atenção. Vendo sua capacidade de prender e reter a atenção de um número significativo de pessoas insensíveis, eles devem inovar para adaptar seu discurso a essas novas condições. [...] 
Trata-se, em suma, de estreitar as preferências dos consumidores, de modo a aumentar a pertinência e, consequentemente, a atração do discurso jornalístico (BRIN, CHARRON, BONVILLE, 2004, p. 31).

Assim, Adghirni (2012, p. 74) dizque "a principal mudança observada nos jornais que já tinham se firmado como polos da indústria cultural é a diversificação de seus produtos".

Contudo, o modelo adotado pelos webjornais era diferente daquele seguido historicamente pelos jornais impressos: "ao invés de buscar a sustentação econômica e uma combinação variável de receita publicitária e de circulação, adotaram o modelo da radiodifusão aberta: sustentação apenas pela publicidade e acesso gratuito" (MULLER, 2012, p. 159). Porém, por conta da crise do modelo de negócios dos jornais impressos e da expansão não suficientemente rápida das versões digitais, as organizações jornalísticas passaram a testar modelos híbridos de acesso às edições digitais no final dos anos 1990 e início dos anos 2000 (parcialmente gratuito ou gratuito para assinantes das edições impressas) (MULLER, 2012).

Por conseguinte, o discurso da convergência é o "novo imperador da ordem" nas organizações jornalísticas (ADGHIRNI, 2012, p. 74). Nesse sentido, a autora cita exemplos de jornais de referência brasileiros que integraram as redações do impresso e do online, como $O$ Estado de S. Paulo, em 2009, e a Folha de S. Paulo, em 2010. Para Muller (2012), esta pode ser considerada uma das medidas tomadas pelas organizações para reduzir custos e ganhar coesão.

\section{Transformações e desafios \\ frente aos dispositivos móveis: smartphones e tablets}

A convergência jornalística e o jornalismo em dispositivos móveis trazem inovações para os processos de produção, circulação e consumo de notícias (BARBOSA et al., 2013). Os dispositivos móveis têm modificado a fisionomia, as funcionalidades e as formas como os usuários se relacionam com a internet e a web.

$\mathrm{O}$ uso desses artefatos introduziu a tactilidade como mais um atributo das mídias digitais. Para Palácios e Cunha (2012), a tactilidade vem se somar às seis características dos espaços de informação na internet (hipertextualidade, interatividade, multimidialidade ou convergência, personalização, atualização contínua e memória), tornando-se "elemento essencial para comunicação em aplicativos instalados nesses dispositivos móveis, que utilizam o recurso do touchscreen ou tela sensível ao toque" (PALACIOS, CUNHA, 2012).

Em dezembro de 2014, foi lançado o livro Webjornalismo: 7 características que marcam a diferença. Organizado pelo professor português João Canavilhas, além das seis conhecidas características da notícia nos meios digitais, a obra traz a ubiquidade como o " $7^{\circ}$ princípio do jornalismo na era digital". No capítulo referente a este novo atributo, Pavlik o define como:

No contexto da mídia, ubiquidade implica que qualquer um, em qualquer lugar, tem acesso potencial a uma rede de 
comunicação interativa em tempo real. Quer dizer que todos podem não apenas acessar notícias e entretenimento, mas participar e fornecer sua própria contribuição com conteúdos para compartilhamento e distribuição global. Além disso, o conteúdo noticioso emana de uma variedade de fontes cada vez mais ubíquas, incluindo câmeras de segurança ou vigilância bem como sensores de muitos tipos e formatos, frequentemente ligados à internet. (PAVLIK, 2014, p. 160)

A ubiquidade aponta ao menos quatro consequências para o jornalismo no século XXI, segundo Pavlik (2014): 1- A onipresença do jornalismo cidadão "à medida que as tecnologias wearable se tornem triviais na próxima década" (PAVLIK, 2014, p. 167). 2- O crescimento de novas formas narrativas geolocalizadas e imersivas. 3- O crescimento do Big Data e do jornalismo orientado por dados. 4- O declínio da privacidade e sua substituição por uma sociedade da vigilância global.

No atual contexto de convergência, as organizações produzem conteúdo para os mais diversos espaços: impresso, rádio, televisão, sites da web, smartphones, tablets, redes sociais na internet. Essa pratica é definida por Barbosa (2013) como continuum multimídia de fluxo horizontal e dinâmico, na qual a informação passa a ser "embalada" para as mais variadas mídias a fim chegar a um maior número de pessoas:

$\mathrm{O}$ conceito abrange aspectos relacionados aos desenvolvimentos tecnológicos, à absorção de novos procedimentos para realizar os processos e rotinas de produção do jornalismo, como também os avanços já empreendidos nos estudos para o melhor entendimento do fenômeno da convergência jornalística, suas particularidades, consequências e também divergências. Ademais, continuum multimídia compõe um dos traços característicos para o que se depreende como novo estágio de evolução para o jomalismo em redes digitais (BARBOSA, 2013, p. 38).

A evolução do jornalismo em redes digitais encontra-se eu seu quinto estágio $^{4}$ e tem como propulsores os dispositivos móveis, uma vez que eles reconfiguram a produção, a circulação, o consumo e a recirculação de informações, assim como modificam as rotinas das redações e as habilidades dos jornalistas que precisam atuar agora com novos produtos, como os aplicativos (apps) jornalísticos (BARBOSA et al., 2013).

Uma das principais características deste quinto estágio do jornalismo nas redes digitais é a medialidade, que, segundo Barbosa (2013), vê todas as mídias como complementares e não concorrentes:

$\mathrm{Na}$ contemporaneidade a produção jornalística presente nos diversos formatos de conteúdos (textos, fotos, áudios, vídeos, infográficos,
${ }^{4}$ Mielniczuk (2003) divide em três momentos os produtos jornalísticos desenvolvidos para a web. Primeira geração (fase da transposição): quando os produtos eram apenas cópias do jornal impresso. Segunda geração (fase da metáfora): os produtos ainda eram ligados ao modelo do jornal impresso, entretanto, as empresas começam a explorar as ferramentas da rede. Terceira geração (fase da exploração das características do suporte web): passam a surgir tentativas de explorar e colocar em prática as potencialidades oferecidas pela web para fins jornalisticos. A quarta geração é definida por Barbosa (2008), tendo como elemento estruturante as bases de dados. 
slideshows, newsgames,

linhas de tempo etc) criados, editados, distribuídos pelas organizações jornalísticas para multiplataformas é totalmente realizada por profissionais, empregando tecnologias digitais e em rede. As atuais rotinas de produção pressupõem $\mathrm{o}$ emprego de softwares, de bases de dados, algoritmos, linguagens de programação e de publicação, sistemas de gerenciamento de informações, técnicas de visualização, metadados semânticos, entre outros. Dessa maneira, já não se tem uma oposição entre meios antigos/ tradicionais e os new media (BARBOSA, 2013, p. 34).

Como exemplo, podemos citar os jornais de referência $\mathrm{O}$ Estado de $\mathrm{S}$. Paulo e Folha de S. Paulo. Os dois jornais impressos estão entre os mais tradicionais do país. No entanto, desde o início da internet comercial possuem websites

${ }^{5}$ Formado pelo jornal O Estado de S. Paulo, portal Estadão, Agência Estado, Rádio Eldorado e Oesp Estadão, além dos sites Limão e Território Eldorado. O carro-chefe do grupo é o jornal $O$ Estado de S. Paulo.

${ }^{6} E$ tido como um dos principais conglomerados de mídia do pais. Fazem parte do grupo: o jornal Folha de S. Paulo, a empresa de conteúdo e serviços de internet $U O L, o$ portal Folha.com, a agência de notícias Folhapress, o instituto de pesquisa Datafolha, entre outros. e têm investido em conteúdos digitais. Com a emergência das redes sociais na internet e dos dispositivos móveis não foi diferente.

O jornal O Estado de S. Paulo, que faz parte do grupo Estado ${ }^{5}$, possui perfis em redes sociais na internet como Twitter, Facebook e Instagram, além de aplicativos para smartphones e tablets. O portal Estadão pode ser acessado pelos dispositivos móveis tanto pelos navegadores como por aplicativos, mas os destaques são os produtos autóctones, aqueles específicos para as mídias móveis, como o Estadão Noite (edição vespertina para tablets com análises de especialistas sobre os principais acontecimentos do dia).

Com perfis nas redes sociais Twitter, Facebook e Instagram, o jornal Folha de S. Paulo, do Grupo Folha ${ }^{6}$, também tem investido em produtos para dispositivos móveis, tendo aplicativos com as versões digitais tanto do jornal impresso como do portal Folha.com.

A criação desses novos produtos para smartphones e tablets é algo recente, o que inicia um novo ciclo de inovação (BARBOSA, 2013). Dentre os produtos mais inovadores estão os autóctones, aplicações criadas de forma nativa com material exclusivo e tratamento diferenciado (BARBOSA, FIRMINO DA SILVA, NOGUEIRA, 2012). Segundo Barbosa et al. (2013), esses produtos demandam enfoque e narrativas diferenciadas dos demais, indicando maneiras distintas de pensar, apurar e estruturar as notícias.

Outra novidade é o retorno das edições vespertinas, como é o caso do aplicativo Estadão Noite, do grupo Estado, motivado pelas características de leitura de mídias como os tablets. Este aplicativo não é gratuito. Para ter acesso a ele, é preciso fazer a assinatura do produto ou pagar pela edição avulsa.

Atualmente, as organizações jornalísticas estão tentando consolidar um novo modelo de negócio com os aplicativos (apps). Segundo Aguado e Castellet (2013, p. 34, tradução nossa), “o processo de plataformização coloca o conteúdo digital [...] no coração do ecossistema da mobilidade", uma vez que "o futuro dos dispositivos móveis gira em torno do conteúdo em conectividade". Assim, por conta da expansão da banda larga móvel, há uma mudança “de um modelo on portal, submetido ao controle 
das operadoras, a um off portal, com acesso direto dos usuários e suas métricas" (AGUADO, CASTELLET, 2013, p. 36), marcando o início de um modelo de negócios que complementa as estratégias da internet fixa. Logo, se em um primeiro momento os usuários necessitavam estar conectados para consumir conteúdo nos portais, nesta nova fase, ao baixar o aplicativo de uma revista e comprar uma edição digital, o usuário poderá consumi-la sem, necessariamente, estar conectado à rede.

Por conseguinte, a necessidade de aproximação do jornalista com as equipes de design e da programação, na busca por layouts e funcionalidades adequadas para os dispositivos móveis, também tem sido apontada por Barbosa et al. (2013) como uma mudança no trabalho jornalístico.

Nesse sentindo, é interessante resgatarmos a tese doutoral de Bertocchi (2014). Ao falar sobre o papel do jornalista no sistema narrativo do jornalismo digital, a autora sugere que o profissional passe a entender melhor o funcionamento do sistema, pois, normalmente, o jornalista atua somente na camada mais superficial do sistema que é relativa ao formato (BERTOCCHI, 2014). Com os jornalistas compreendendo melhor como se dá esse processo e trabalhando juntamente com as equipes de design e da programação, poderíamos ter produtos jornalísticos que melhor utilizassem as potencialidades do meio digital.

Bertocchi (2014) coloca o papel do jornalista como o de "um designer de experiência: ele não apenas 'escreve o texto', mas é a figura também capaz de modelar a narrativa em camadas, com equipes humanas e robôs, tendo como objetivo uma experiência narrativa centrada nos usuários" (2014, p. 13). Nesse momento, o papel do jornalista deixa de ser visto sob a perspectiva do selecionador ${ }^{7}$ e passa a ser considerado como o protagonista desse processo. Esse é um ponto de vista extremamente relevante, pois a autora resgata uma função que é genuína do jornalista e vinha sendo perdida.

\section{Considerações finais}

Neste artigo, buscamos trazer algumas reflexões sobre as reconfigurações pelas quais o jornalismo tem passado com a emergência das tecnologias digitais, com enfoque nos dispositivos móveis, considerando o atual processo de convergência, e, por conseguinte, a distribuição de conteúdo em multiplataformas.

Porserumaprática social,ojornalismo, assim como a sociedade, passa por transformações. Contudo, entendemos que ocorre uma reconfiguração dos produtos jornalísticos, do modelo de negócios das organizações noticiosas e do papel do jornalista. Assim, dentre as principais transformações e desafios ocorridos no atual panorama do jornalismo convergente com as redes digitais, em relação aos seus produtos e suas práticas, podemos citar:

- A emergência de novos atributos para a informação noticiosa em redes digitais móveis (a tactilidade e a ubiquidade) (PALACIOS, CUNHA, 2012; PAVLIK, 2014);

- A criação de novos produtos jornalísticos (os aplicativos)
${ }^{7}$ Com a emergência das redes digitais, alguns autores afirmam que agora o jornalista ganha um novo papel: o de selecionar os conteúdos confiáveis da internet. 
BARBOSA et al., 2013);

- O surgimento de um novo modelo de negócios (baseado em aplicativos e na cobrança pelo conteúdo) (AGUADO, CASTELLET, 2013);

- A necessidade de novas rotinas e habilidades de trabalho (aproximação do jornalista com as equipes de design e da programação, e conhecimento do sistema por parte do jornalista, para que ele possa saber o que é possível ser feito ou não, tornando-se o protagonista do processo de construção da notícia) (BARBOSA et al., 2013, BERTOCCHI, 2014).

A crise dos jornais ainda existe. Muitos periódicos de tradição impressa fecharam, outros existem agora apenas na versão digital. Mas não podemos negar que no atual contexto da convergência jornalística as empresas têm se reinventado, criando novos produtos e tentando atingir novos públicos. Essa diversificação e superabundância de oferta é uma característica do atual paradigma do jornalismo de comunicação e configura-se como uma estratégia do jornalismo convergente para conseguir novos consumidores e manter os atuais, concomitantemente. Dessa forma, distribuindo conteúdo em multiplataformas, para um público tradicional e para outro conectado, as organizações jornalísticas vão enfrentando os seus desafios.

\section{Referências bibliográficas}

ADGHIRNI, Zélia Leal. Mudanças estruturais no jornalismo: travessia de uma zona de turbulência. In: PEREIRA, Fábio; MOURA, Dione; ADGHIRNI, Zélia Leal (orgs.). Jornalismo e Sociedade: teorias e metodologias. Florianópolis: Insular, 2012.

AGUADO, Miguel; CASTELlet, Andreu. Contenidos digitales en el entorno móvil: mapa de situación para marcas informativas y usuários. In: BARBOSA, Suzana; MIELNICZUK, Luciana (Orgs.). Jornalismo e Tecnologias Móveis. Covilhã: Livros LabCOM, 2013.

BARBOSA, Suzana. Jornalismo convergente e continuum multimídia na quinta geração do jornalismo nas redes digitais. In: CANAVILHAS, João (Org.). Notícias e Mobilidade: O Jornalismo na Era dos Dispositivos Móveis. Covilhã: Livros Labcom, 2013.

Convergência jornalística em curso: as iniciativas para integração de redações no Brasil. In: RODRIGUES, Carla (Org.). Jornalismo On-line: modos de fazer. Rio de Janeiro: Ed.PUC-Rio: Sulina, 2009.

Modelo JDBD e o ciberjornalismo de quarta geração. (2008). Disponível em <http://www.facom.ufba.br/jol/pdf/2008_Barbosa_RedUCMx.pdf> Acesso em: 18 abr 2011.

BARBOSA, Suzana et al. "A atuação jornalísticaem plataformas móveis.” Estudo sobre produtos autóctones e a mudança no estatuto do jornalista. In: Brazilian Journalism Research, v. 9, n.2, p. 10-29, 2013. 
convergência de conteúdos em produtos jornalísticos com presença multiplataforma. In: Anais $10^{\circ}$ Encontro Nacional de Pesquisadores em Jornalismo - SBPJor. Curitiba, Brasil: novembro de 2012.

BERTOCCHI, Daniela. Dos dados aos formatos: o sistema narrativo no jornalismo digital. In: Anais do XXIII Encontro Anual da Compós. Belém, Brasil: maio de 2012.

BRIN, Colette; CHARRON, Jean e BONVILLE, Jean de. Natureza e transformação do jornalismo - Teoria e pesquisas empíricas. Tradução: Márcia Marques e Rogério dy lá Fuente Gonçalves. No prelo.

JENKINS, Henry. Cultura da Convergência. 2 ed. São Paulo: Aleph, 2009

KOLODZY, Janet. Convergence journalism - writing and reporting across the news media. Oxford (UK): Rowman \& Littlefield publishers, 2006.

LEMOS, André. Ciber-cultura-remix. In: Seminário de "Sentidos e processos". São Paulo. 2005. Disponível em <http:/www.facom.ufba.br/ciberpesquisa/andrelemos/ remix.pdf>. Acesso em: 10 abr 2013.

MIELNICZUK, Luciana. Sistematizando alguns conceitos sobre jornalismo na web. In: MACHADO, Elias; PALACIOS, Marcos (Orgs). Modelos de Jornalismo Digital. Salvador: Edições GJOL; Calandra, 2003.

MÜLLER, Carlos Alves. A crise estrutural dos jornais e o surgimento das mídias digitais: impactos sobre a produção jornalística. In: PEREIRA, Fábio; MOURA, Dione; ADGHIRNI, Zélia Leal (Orgs.). Jornalismo e Sociedade: teorias e metodologias. Florianópolis: Insular, 2012.

PALACIOS, Marcos Silva; CUNHA, Rodrigo do Espírito Santo da. A tactilidade em dispositivos móveis: primeiras reflexões e ensaio de tipologias. In: Contemporânea (UFBA. Online), v. 10, p. 668-685, 2012.

PAVLIK, John V. Ubiquidade: 0 7. ${ }^{\circ}$ princípio do jornalismo na era digital. In: CANAVILHAS, João (Org.). WebJornalismo: 7 Caraterísticas que marcam a diferença. Covilhã: Livros LabCOM, 2014.

SALAVERRÍA, Ramón; GARCIAAVILÉS, José Alberto; MASIP, Pere Masip. Concepto de convergencia periodística. In: LÓPEZ GARCIA, Xosé; PEREIRA FARIÑA, Xosé (Orgs.). Convergencia Digital: Reconfiguración de los médios de comunicación en España. Santiago de Compostela: Servizo de Publicaciones e Intercambio Científico, Universidade de Santiago de Compostela, 2010.

SALAVERRÍA, Ramón. Estructura de la convergencia. In: LÓPEZ GARCIA, Xosé; PEREIRA FARIÑA, Xosé (Orgs.). Convergencia Digital: Reconfiguración de los médios de comunicación en España. Santiago de Compostela: Servizo de Publicaciones e Intercambio Científico, Universidade de Santiago de Compostela, 2010.

Estudos em Jornalismo e Mídia está sob a licença Creative Commons 2.5 